\title{
Clinical and radiological survey of the incidence of osteoarthrosis among obese patients
}

\author{
RICHARD H. GOLDIN, LAWRENCE MCADAM, JAMES S. LOUIE, RICHARD \\ GOLD, AND RODNEY BLUESTONE
}

From the Medical and Research Services, Wadsworth Hospital Center, Los Angeles; the Department of Radiology, UCLA School of Medicine, Los Angeles; Harbor General Hospital, Torrance, California, U.S.A.

\begin{abstract}
Goldin, R. H., McAdam, L., Louie, J. S., Gold, R., and Bluestone, R. (1976). Annals of the Rheumatic Diseases, 35, 349-353. Clinical and radiological survey of the incidence of osteoarthrosis among obese patients. Twenty-five grossly obese males were investigated for evidence of osteoarthrosis. A roentgenological survey of multiple joints obtained from 22 of these patients showed few significant degenerative changes. 6 patients $(20 \%)$ had previously incurred traumatic rents in their menisci necessitating meniscectomy. Our results refute previous claims that obesity is a factor in the genesis of osteoarthrosis but do indicate that obese individuals are more predisposed to traumatic injury of the knee.
\end{abstract}

The role of obesity as an aetiological factor in osteoarthrosis (OA) remains controversial. It is thought that excessive weight is a factor in promoting joint degeneration, and invariably it is recommended to the obese patient with $\mathrm{OA}$ that he or she lose weight. The logic of this recommendation is irrefutable, but its basis in scientific fact is less clear.

Large population studies of patients with OA have shown that a great number are obese (Kellgren and Lawrence, 1958; Kellgren, 1961; Lawrence, Bremmer, and Bier, 1966). A relationship has also been suggested between obesity and the development of $\mathrm{OA}$ in specific weight-bearing joints such as knees (Leach, Baumgard, and Broom, 1973) and hips (Law, 1964). Curiously, corpulent individuals have also been found to have an increased incidence of OA in nonweight-bearing joints such as the sternoclavicular joint (Silberberg and others, 1959) and distal interphalangeal joints (Kellgren, 1961). Other reports say nothing about obese individuals having increased difficulties because of OA. Danielsson and Hernborg (1970) and Miller and others, (1973) were unable to find an increase in body weight among women with degenerative changes of the knees as compared with women with no changes; and Stecher (1955) was unable to relate obesity to the development of Heberden's nodes.
The following study was designed as an attempt to further elucidate any relationship between obesity and degenerative joint disease. 25 males who had carried weights at least two times their ideal weights for many years were evaluated for clinical or radiological evidence of articular disease.

\section{Methods and materials}

Twenty-five males, under study in the Obesity Research Program of the Wadsworth Veterans Administration Hospital, Los Angeles, were evaluated for clinical and radiological evidence of $O A$. Each had maintained his body weight at more than two times the ideal for many years. So severe was the obesity in these patients, and so opposed were they to conservative management that jejunolileal bypass surgery was either contemplated or had recently been performed. A history was obtained from each individual as to age, occupation, dietary habits, maximum weight, duration of obesity, treatments for obesity, previous trauma, joint complaints, and the presence of any associated medical problems. The ideal body weight for each patient according to his height was assessed from tables compiled by the Metropolitan Life Insurance Company of North America. A complete physical examination with emphasis on the evaluation of the joints was conducted on each patient. Laboratory data, including 2-hour postprandial glucose, triglycerides, cholesterol, uric acid, erythrocyte sedimentation rate, antinuclear antibody, and rheumatoid factor, were taken from the medical records when available. 
Standard radiographs of 22 of the 25 patients included (1) anteroposterior views of the knees at a $6^{\prime}$ target-film distance, with the patient standing; (2) lateral views of the knees; (3) anteroposterior view of the pelvis; (4) anteroposterior and lateral views of the lumbar spine, (5) ankles, and (6) feet; and (7) posteroanterior views of both hands and wrists. If appropriate radiographs taken recently were available, they were not repeated. In 2 of the 22 patients radiographs of the hands were inadvertently not taken, and in another patient the knees were not $x$-rayed.

Each radiograph was evaluated by one of us (R.G.) in the absence of clinical information and age status. OA was diagnosed according to features described and illustrated in an Atlas of Standard Radiographs of Arthritis (Council for International Organization, 1963). (a) Osteophytes at the joint margins or at sites of ligamentous attachment; (b) periarticular ossicles in the hands and wrists; (c) narrowing of the distance between the bony margins at the articular ends of bones, associated with subchondral bone sclerosis; (d) cystic areas in the subchondral bone; (e) alteration of the shape of the bone ends. In the radiological evaluation of each joint all of these changes were considered together in four possible grades of severity: $0=$ none, $1=$ minimal, $2=$ moderate, $3=$ severe.

Table I Clinical data of 25 obese male patients

\begin{tabular}{|c|c|c|c|c|c|c|}
\hline Case no. & $\begin{array}{l}\text { Age } \\
\text { (years) }\end{array}$ & $\begin{array}{l}\text { Height } \\
\text { (cm) }\end{array}$ & $\begin{array}{l}\text { Weight } \\
(\text { kg) }\end{array}$ & $\begin{array}{l}\text { Ideal } \\
\text { weight } \\
(\mathrm{kg})\end{array}$ & $\begin{array}{l}\text { Maximum } \\
\text { weight } \\
(k g)\end{array}$ & $\begin{array}{l}\text { Duration of } \\
\text { obesity } \\
\text { (years) }\end{array}$ \\
\hline $1^{*}$ & 54 & 176 & $70 \cdot 4$ & 67 & 176 & 12 \\
\hline $2^{*}$ & 50 & 170 & $116 \cdot 2$ & 63 & 145 & 30 \\
\hline 3 & 40 & 171 & 175 & 65 & 175 & 22 \\
\hline 4 & 38 & 190 & 159 & 79 & 161 & 19 \\
\hline 5 & 48 & 181 & 120 & 74 & 165 & 18 \\
\hline 6 & 43 & 171 & 122 & 65 & 131 & 8 \\
\hline 7* & 50 & 176 & 147 & 67 & 147 & 30 \\
\hline 8 & 26 & 185 & 149 & 75 & 149 & 21 \\
\hline 9 & 46 & 177 & 170 & 69 & 170 & 25 \\
\hline $10^{*}$ & 40 & 190 & 122 & 79 & 221 & 23 \\
\hline 11 & 41 & 182 & 121 & 74 & 121 & 22 \\
\hline 12 & 38 & 190 & 154 & 79 & 154 & 18 \\
\hline 13 & 39 & 182 & 149 & 74 & 165 & 19 \\
\hline 14 & 46 & 168 & 113 & 63 & 113 & 20 \\
\hline 15 & 52 & 177 & 167 & 69 & 170 & 25 \\
\hline 16 & 49 & 160 & 131 & 58 & 145 & 15 \\
\hline $17^{*}$ & 50 & 173 & 147 & 67 & 192 & 15 \\
\hline 18 & 41 & 172 & 118 & 65 & 143 & 24 \\
\hline 19 & 46 & 193 & 214 & 82 & 227 & 20 \\
\hline 20 & 52 & 160 & 142 & 58 & 163 & 27 \\
\hline 21 & 49 & 179 & 153 & 71 & 153 & 9 \\
\hline 22 & 54 & 180 & 227 & 71 & 227 & 10 \\
\hline 23 & 48 & 187 & 139 & 77 & 139 & 31 \\
\hline $24^{*}$ & 46 & 160 & 65 & 58 & 163 & 28 \\
\hline 25 & 33 & 158 & 143 & 63 & 152 & 14 \\
\hline
\end{tabular}




\section{Results}

\section{CLINICAL (TABLE I)}

The mean age of 25 male patients was $44 \cdot 7$ years, range $26-54$ years. The average body weight of the group at the time of evaluation was $178 \mathrm{~kg}, 91 \mathrm{~kg}$ higher than the mean of their ideal weights. This mean difference is probably too small because 6 patients had recently undergone intestinal bypass surgery and the weights of 5 of these had dropped significantly at the time of evaluation. The mean of the previous maximum weights for all the patients was $201 \mathrm{~kg}, 114 \mathrm{~kg}$ above the mean of the ideal weights. These patients had been obese an average of $19 \cdot 3$ years (range $8-30$ years).

Fifteen patients reported a history of arthralgias in a total of 20 joints, including knees 7 , lumbar spine 5 , and elbow 3 ; and there were sporadic complaints of ankle, shoulder, hip, and hand pain. 6 patients complained of joint swelling in the past but manifested no swelling at the time of physical examination. 3 of these 6 patients had had uric acid crystals present in fluid aspirated from inflamed joints. 5 obese patients had undergone a total of 7 meniscectomies because of knee trauma. All had been grossly obese at the time of their injury and surgery. There were no signs of joint inflammation or deformity in any patient at the time of physical examination. There was no evidence by history or

Table II Radiographic changes of $O A$ for each group of joints graded as to severity (see text)

\begin{tabular}{|c|c|c|c|c|}
\hline \multirow[b]{2}{*}{ Joint } & \multicolumn{4}{|c|}{ Grade } \\
\hline & 0 & 1 & 2 & 3 \\
\hline Hands (40) & 14 & 25 & 1 & 0 \\
\hline Hips (44) & 29 & 12 & 0 & 3 \\
\hline Knees (42) & 22 & 15 & 3 & 2 \\
\hline Ankles (44) & 40 & 4 & 0 & 0 \\
\hline Feet* (44) & 31 & 12 & 1 & 0 \\
\hline Sacroiliacs (44) & 44 & 0 & 0 & 0 \\
\hline Symphysis pubis $†$ (22) & 17 & 3 & $\mathbf{0}$ & 0 \\
\hline $\begin{array}{l}\text { Lumbosacral spine (22) } \\
\text { L1-2 }\end{array}$ & 21 & $\mathbf{0}$ & 1 & 0 \\
\hline L2-3 & 22 & 0 & 0 & $\mathbf{0}$ \\
\hline L3-4 & 21 & 1 & 0 & 0 \\
\hline L4-5 & 16 & 3 & 0 & 3 \\
\hline L5-S1 & 17 & 1 & 2 & 2 \\
\hline
\end{tabular}

*All OA changes occurred at 1st metatarsophalangeal joint. + Width of symphysis $>6 \mathrm{~mm}$.

No. of joints examined in parentheses. physical examination of the polyarthritis associated with intestinal bypass procedures.

Eight patients had abnormal 2-hour postprandial glucose values recorded. None had serum antinuclear antibody, rheumatoid factor, or abnormal blood sedimentation rates.

\section{RADIOGRAPHIC (TABLE II)}

Roentgenological evaluation showed no significant changes of $\mathrm{OA}$ in the joints of the 22 patients studied. Minimal changes were found occasionally in the knees, hips, hands, and first metatarsophalangeal joints. Moderate or severe changes were found in the knees and rarely in the hips of those patients only who had undergone meniscectomy. Radiographic changes of degenerative intervertebral disc disease, moderate or severe in extent, were found in 6 patients, predominating at the fourth and fifth lumbar to first sacral levels.

\section{Discussion}

In the present study of the relationship between OA and obesity it was decided to look at grossly obese patients for evidence of degenerative joint disease. This was the reverse of all previous studies where the emphasis has been on descriptions of the body habitus of patients who primarily had degenerative joint disease. Kellgren and Lawrence (1958) conducted population surveys of the prevalence of arthritis in an English town. The effects of factors including body weight were evaluated for any aetiological relationship to the pattern of joint disease. Any persons more than $10 \%$ above average weight were considered to be obese, by which definition $27 \%$ of males and $44 \%$ of females with OA were overweight. Weight-bearing joints, such as knees, and the first metatarsophalangeal joints were more commonly affected in obese individuals of both sexes. The lumbar spine and distal interphalangeal joints of the fingers were commonly involved in portly males. Lacking in this report, however, is any detailed information regarding the degree or duration of obesity, and the temporal relationship between the development of a weight problem and the onset of arthritic complaints. It is conceivable that rather than being the cause of OA, as has been heretofore postulated, obesity may be a secondary result of the pain and inactivity attendant upon a patient with degenerative joint disease.

Leach and others (1973) studied the weight distribution of 200 patients with OA of the knees and tried to determine the age of onset of obesity but were thwarted by the reluctance of patients with OA to admit to their corpulence. Compared with a control population of 200 orthopaedic patients of normal weight who did not have degenerative joint disease of the knees, there was a high percentage of 
obesity among women with OA of the knees but not among the men. Others have not noted an increase in body weight among women with radiographic change of $\mathrm{OA}$ of the knees (Danielsson and Hernborg, 1970; Miller and others, 1973),

Investigators studying $\mathrm{OA}$ of the hip have not found any increased frequency of obesity among these patients, though Law (1964) stated that such a relationship did exist without offering supportive evidence for his statement. Saville and Dickson (1968) investigated the frequency of obesity among 121 patients with primary or secondary OA of the hip. Neither men nor women with joint disability showed any tendency towards being overweight.

An interesting association has been reported between obesity and nonweight-bearing joints such as the distal interphalangeal joints of the fingers (Kellgren and Lawrence, 1958). Stecher (1955) studied patients with Heberden's nodes and found no association with body weight. In a post-mortem study of 200 sternoclavicular joints, Silberberg and others (1959) found little evidence in favour of obesity as a primary factor in the development of OA of this joint. However, there was a tendency for young obese individuals to have an especially high incidence of severe lesions at this location. Since the sternoclavicular joint is nonweight-bearing, any link between obesity and OA was thought by Silberberg and others to be based upon conditions other than mechanical factors.

Seltzer (1943) performed anthropometric measurements on 38 patients with OA and 112 patients with rheumatoid arthritis and found that the patients with degenerative joint disease tended to be larger in most body measurements. This, of course, is not surprising as patients with rheumatoid arthritis may have a systemic disease with weight loss as a common accompanying feature. Engel (1968) did a similar study of body measurements among patients with $\mathrm{OA}$ and found that patients with disease of both weight-bearing and nonweight-bearing joints had a greater body weight, increased body fat, and increased arm girth than a normal control population.

Animal studies have also been less than conclusive in relating obesity to the development of OA. Sokoloff and others (1960) studied obese and nonobese mice and did not find a consistent pattern of increased body weight with the presence of OA. Dietary restriction of those animals known to develop obesity and degenerative joint disease spontaneously did not decrease the degree of joint disease even though it resulted in slimmer mice. This finding is in contrast to the results of Silberberg, Jarrett, and Silberberg (1956) who noted that mice with extreme obesity had a marked increase of OA while slight or moderate degrees of obesity showed no relationship to the presence of degenerative joint disease and that the development of OA in mice was retarded when caloric intake was restricted.

The present study was designed to examine individuals with extreme obesity for evidence of OA. Our patients carried weights greater than double their ideal weights for an average of almost two decades. These weights were far greater than those in previous studies where obesity was defined as any poundage greater than $10 \%$ over average body weight (Kellgren and Lawrence, 1958) or greater than 2 standard deviations above the median weight for a particular height (Leach and others, 1973). In addition we were better able to assess the degree of obesity, duration, and time of onset of obesity because our population, having sought treatment for their obesity, were not reluctant to discuss their problem. Our results showed neither clinical nor radiological evidence of significant osteoarthrotic changes among this patient population. Minimal changes of $\mathrm{OA}$ were no more frequent than those usually noted in the radiographs of males of normal body weight. Of interest is the high $(20 \%)$ frequency of knee trauma resulting in meniscectomy among the 25 patients, which implies that the knees of fat persons are at a mechanical disadvantage, making them more susceptible to trauma and meniscal tears.

It is believed that obesity may be a factor in the aetiology of OA by either mechanical or nutritional means. That mechanical factors are important in the genesis of degenerative joint disease has been intimated by the association of specific joint involvement and certain physical activities. Hence, pneumatic drill operators tend to manifest OA of the elbows, shoulders, and wrists (Hunter, McLaughlin, and Perry, 1945), baseball catchers OA of the fingers, and ballet performers have joint problems in their feet (Brodelius, 1961). Mechanical factors have been emphasized by Radin, Paul, and Rose (1972), who propose that repetitive impulsive loading applied across a joint results in microfractures with resultant sclerosis of the subchondral bone. The cartilage overlying this bone is thereby subjected to forces which cannot be properly dampened by the stiffer bone and the cartilage tends to break down. Denham (1959) has shown that there is a markedly increased pressure across the hip joint of an obese patient and that the loss of 1 pound of body weight could relieve the joint of 3 pounds of pressure. Whether or not this added pressure is converted in an obese patient to enough mechanical stress to cause premature or progressive joint destruction is not known. It may be that our patients were so excessively overweight as to be relatively immobile. Thus, active joint motion was depressed to such a degree that they developed little stress to their joints and hence little joint damage. Thus there may be a critical weight beyond which 
immobility becomes protective to joints. This has been seen in stroke patients with inflammatory arthritis where an immobilized limb is seen to develop few articular changes as compared to the mobile contralateral limb.

Obese individuals often have abnormal glucose tolerance and raised serum lipids, both of which have been implicated as factors in the genesis of OA. Silberberg and others (1959) found a positive correlation between $\mathrm{OA}$ and diabetes, and also showed (1956) that both high fat and high carbohydrate diets exerted an injurious effect on the joints of mice. However, these results were not confirmed by Sokoloff and Mickelsen (1965) in similar experiments. 8 of our patients had abnormalities of glucose tolerance as determined by a 2-hour postprandial glucose test but none of these had excessive degenerative joint disease. None of those tested had significantly abnormal serum triglyceride or cholesterol concentrations.

\section{Conclusion}

The question of whether obesity relates to the aetiology of OA remains unresolved. The present study indicates that such a relationship does not exist. However, the number of patients studied was small and a review of a larger population of obese patients may give different data. There is as yet no solid evidence that overweight individuals are more prone to the ravages of $\mathrm{OA}$. Obesity may result in excessive stress upon the menisci of the knee leading to increased susceptibility of the menisci to injury.

\section{Supported by USPHS grant GM 15759.}

\section{References}

Brodelius, A. (1961) Acta orthop. Scand., 30, 309 (Osteoarthrosis of the talar joints in footballers and ballet dancers)

Council for International Organization of Medical Sciences (1963) 'The epidemiology of chronic rheumatism', Vol. II in 'Atlas of Standard Radiographs of Arthritis'. Blackwell Scientific Publications, Oxford

Danielsson, L., AND Herniorg, J. (1970) Clin. Orthop., 69, 302 (Clinical and roentgenologic study of knee joints with osteophytes)

DenhaM, R. A. (1959) J. Bone Jt Surg., 41B, 550 (Hip mechanics)

Engel, A. (1968) 'Osteoarthritis and body measurements'. Publication 1000, 29, U.S. Public Health Service, Washington, D.C.

Hunter, D. A., McLaughlin, A. I. G., ANd PerRy, K. M. A. (1945) Brit. J. industr. Med., 2, 10 (Clinical effects of use of pneumatic tools)

KellgReN, J. H. (1961) Brit. med. J., 2, 1. (Osteoarthrosis in patients and populations)

- AND LaWrence, J. S. (1958) Ann. rheum. Dis., 17, 388 (Osteoarthrosis and disk degeneration in an urban population)

LAw, W. A. (1964) Practitioner, 193, 585 (Osteoarthritis of the hip)

LaWrence, J. S., Bremmer, J. M., AND Bier, F. (1966) Ann. rheum. Dis., 25, 1 (Osteoarthrosis. Prevalence in the population and relationship between symptoms and $x$-ray changes)

LEACH, R. E., BAUMgaRD, S., AND BROOM, J. (1973) Clin. orthop., 93, 271 (Obesity: its relationship to osteoarthritis of the knee)

Miller, R., Kettlekamp, D. B., Laubenthal, K. N., Karagiorgos, A., and Smidt, G. L. (1973) J. Bone $J t$ Surg., 55A, 956 (Quantitative correlations in degenerative arthritis of the knee)

Radin, E. L., PAUl, I. L., AND Rose, R. M. (1972) Lancet, 1, 519 (Role of mechanical factors in the pathogenesis of primary osteoarthrosis)

Saville, P. D., AND Dickson, J. (1968) Arthr. and Rheum., 11, 635 (Age and weight in osteoarthritis of the hip)

Seltzer, C. C. (1943) Medicine, 22, 163 (Anthropometry and arthritis)

Silberberg, M., JARrett, S. F., AND Silberberg, R. (1956) Arch. Path., 61, 280 (Obesity and degenerative joint disease; experiments in 'yellow' mice)

—, Frank, E. L., Jarrett, S. R., AND Silberbérg, R. (1959) Amer. J. Path., 35, 851 (Aging and osteoarthritis of the human sternoclavicular joint)

SOKOLOFF, L., AND MiCKELSEN, O. (1965) J. Nutr., 85, 117 (Dietary fat supplements, body weight and osteoarthritis in DBA/2JN mice)

- Silverstein, E., Jay, G. E., Jr., ANd Yamamoto, R. S. (1960) Amer. J. Physiol., 198, 765. Experimental obesity and osteoarthritis)

Stecher, R. M. (1955) Ann. rheum. Dis., 14, 1 (Herberden's nodes. A clinical description of osteoarthritis of the finger joints) 